\title{
SMALL SHIPS HYDRODYNAMICS SOFTWARE PLATFORM
}

\author{
Dan Obreja \\ "Dunarea de Jos" University of Galati, \\ Faculty of Naval Architecture, Galati, \\ Domneasca Street, No. 47, 800008, Romania, \\ E-mail: dan.obreja@ugal.ro
}

\begin{abstract}
The hydrodynamics performances prediction of the small ships represents an important issue in the initial design stage. The Preliminary Hydrodynamics Performances (PHP) software platform was developed at the Research Centre of the Naval Architecture Faculty from "Dunarea de Jos" University of Galati, in order to calculate the ship resistance, as well as the powering and manoeuvring performances of the small ships. The description of the most important software modules and corresponding theoretical aspects is presented in this paper. The software platform is used for the didactic applications and research activities dedicated to the estimation of the hydrodynamics performances of the small ships, in the preliminary design stage.
\end{abstract}

Keywords: small ships, resistance, powering, manoeuvring, software platform.

\section{INTRODUCTION}

The estimation of the resistance, powering and manoeuvring performances of the small ships in the initial design stage is a very important problem.

Specific theoretical methods were developed depending on the number of hulls and operating domain (displacement, transient or planning), in order to solve the above mentioned hydrodynamics performances.

The operating mode depends on the value of the Froude number $F n_{\nabla}$, calculated by means of the relation

$$
F n_{\nabla}=\frac{v}{\sqrt{g \cdot \nabla^{1 / 3}}}
$$

where $g$ is the gravity acceleration, $\nabla$ is the volumetric displacement and $\mathrm{v}$ is the ship speed.

Depending on the Froude number $F n_{\nabla}$ value, the following operating domains may be defined:
- Displacement domain, if $F n_{\nabla}<1$;

- Transient domain, if $1<F n_{\nabla}<3$;

- Planning domain, if $F n_{\nabla}>3$.

From the small ship resistance performance point of view, specific methods can be used for mono-hulls and catamarans, in displacement, transient and planning domains [2], [3], [22], [23], [24], [25], [26].

By means of the ship resistance and selection of the optimum propeller characteristics based on the B-Wageningen propeller series, the powering performance of the small ships can be calculated [4], [5].

In the last step of the hydrodynamic analysis, the manoeuvring performance of the small ships must be estimated, including the hydrodynamics characteristics of the rudder. The specific computational methods can be applied depending on the ship operating domain [3], [4], [5].

A fast investigation software platform (PHP-Preliminary Hydrodynamics Perform- 
ances) was generated at the Research Centre of the Naval Architecture Faculty from "Dunarea de Jos" University of Galati, in order to estimate the resistance, powering and manoeuvring performances of the small ships, in the preliminary design stage.

A synthetical description of the specific theoretical methods applied in order to solve the small ships resistance problem both for mono-hulls and catamarans is presented in the next chapter.

\section{SMALL SHIPS RESISTANCE PER- FORMANCE}

The ship resistance problem can be solved on the PHP platform for the following types of small ships: mono-hulls (for displacement, transient and planning domains), catamarans (both with rounded bilge and hard chine forms) and sailing vessels.

The small ship resistance estimation in the case of the mono-hulls in displacement or transient domains was performed by means of the Mordvinov method ([3], [4], [5], [6], [18]). The total ship resistance $R_{T}$ may be calculated using the relation

$$
R_{T}=R+R_{A P P}+R_{A}
$$

where $\mathrm{R}$ is the bare hull resistance notation, $R_{A P P}$ is the appendage resistance and $R_{A}$ is the aerodynamic resistance.

The bare hull resistance is given by the expression

$$
R=R_{F}+R_{P V}+R_{W}
$$

where $R_{F}$ is the frictional resistance, with $R_{P V}$ representing the viscous pressure resistance and $R_{W}$ is the own wave resistance.

The frictional resistance is calculated on the basis of the ITTC 1957 formula, depending on the Reynolds number

$$
R e=\frac{v \cdot L_{W L}}{v}
$$

where $L_{W L}$ is the length of the waterline and $v$ is the kinematic viscosity of the water.

The viscous pressure resistance may be calculated with the following relation

$$
R_{P V}=R_{F} \cdot(\eta-1)
$$

depending on the viscous pressure resistance coefficient, noted with $\eta$.

The own wave resistance $R_{W}$ is determined by using the Papmel relations [3], depending on the critical ship speeds $v_{1}$ and $v_{2}$.

$$
\begin{gathered}
\bullet \quad \text { If } v>v_{2} \\
R_{W}=20 \cdot k \cdot \frac{g \cdot \Delta}{L_{W L} \cdot 10^{3}} \cdot v_{2^{2}} \cdot\left(v / v_{2}\right)^{1 / 2} \\
\bullet \quad \text { If } v_{I}<v<v_{2} \\
R_{W}=C_{B 0} \cdot k \cdot \frac{g \cdot \Delta}{L_{W L} \cdot 10^{3}} \cdot v^{2}
\end{gathered}
$$

where $\Delta$ represents the ship displacement. The critical speeds, the coefficient $C_{B O}$ and the coefficient $k$ may be determined in accordance to reference [3].

The appendages resistance $R_{A P P}$ may be calculated as a fraction of the bare hull resistance and depends on the complexity of the appendages and the ship speed [3]

$$
R_{A P P}=k_{A P P} \cdot R
$$

where $k_{A P P}$ represents the appendages coefficient.

The aerodynamic resistance is given by the relation [3]

$$
R_{A}=C_{A} \cdot \frac{\rho_{a} \cdot\left(v+v_{v}\right)^{2}}{2} \cdot S_{e}
$$

where $C_{A}$ is the aerodynamic coefficient, $\rho_{a}$ is the air density, $v_{v}$ is the wind speed and $S_{e}$ is the aerodynamic surface area (projected on the midship section).

The computer code PHP-NM-RI-DT was developed at the Research Centre of the Naval Architecture Faculty from "Dunarea de Jos" University of Galati, in order to compute the small ship resistance in displacement or transient domains [6], [18] by using the described procedure.

In the case of the mono-hulls planning domain, the resistance performance may be estimated according to the Mordvinov method [3], by means of the relation (2).

The bare hull resistance $\mathrm{R}$ is determined by using the following relation [3] 


$$
R=R_{F}+R_{P}
$$

where $R_{F}$ is the frictional resistance of the equivalent plane plate and $R_{P}$ is the pressure resistance.

The frictional resistance of the equivalent plane plate $R_{F}$ is calculated by means of the Prandtl-Schlichting coefficient, given by the formula

$$
C_{F_{0}}=\frac{0.455}{\left(\log \operatorname{Re}_{l_{w}}\right)^{2,58}}
$$

The Reynolds number $R e_{l w}$ is determined by using the relation

$$
\operatorname{Re}_{l_{w}}=\frac{v \cdot l_{w}}{v}
$$

where $l_{w}$ is the wetted length of the equivalent plane plate.

The pressure resistance $R_{P}$ may be estimated by means of the formula [3]

$$
R_{P}=g \cdot \Delta \cdot \operatorname{tg} \alpha
$$

where $\alpha$ is the attack angle.

The appendages resistance $R_{A P P}$ and the aerodynamic resistance $R_{A}$ may be estimated by using the relations (8) and (9).

The computer code PHP-NM-RI-G was developed at the Research Centre of the Naval Architecture Faculty from "Dunarea de Jos" University of Galati, in order to calculate the small ship resistance in the planning domain [7], [19] by using the described method.

Different methods can be used in order to solve the catamaran resistance problem, depending on the hull forms.

In the case of the hard chine catamarans forms, the method based on the series generated by Pham, Kantimahanthi and Sahoo [22] was selected.

The total resistance of the catamaran may be calculated on the basis of the following relation

$$
R_{\text {Tcat }}=\frac{1}{2} C_{\text {Tcat }} \cdot \rho \cdot v^{2} \cdot S_{w}
$$

where $\rho$ is the water density, $S_{w}$ is the wetted surface area of the catamaran and $C_{\text {Tcat }}$ is the coefficient of the total resistance, calculated by means of the formula

$$
C_{\text {Tcat }}=(1+\gamma \cdot k) \cdot C_{F}+C_{w c a t}
$$

$C_{w c a t}$ is the wave resistance coefficient of the catamaran and $C_{F}$ is the frictional resistance coefficient of the demi-hull. The form factor of the catamaran $(1+\gamma \cdot k)$ may be determined by using the multiple regression analysis of Molland, Wellicome and Couser [2].

The frictional resistance coefficient $C_{F}$ may be determined using ITTC'57 ship model correlation line

$$
C_{F}=\frac{0.075}{(\log \mathrm{Re}-2)^{2}}
$$

The wave resistance coefficient $C_{\text {wcat }}$ can be estimated using the following regression relation proposed by Pham et al. [22]

$$
C_{w c a t}=e^{\alpha} \cdot\left(\frac{L}{B}\right)^{\beta 1} \cdot\left(\frac{B}{T}\right)^{\beta 2} \cdot\left(C_{B}\right)^{\beta 3} \cdot\left(\frac{s}{L}\right)^{\beta 4}
$$

and depends on the regression coefficients $\beta_{i}$ $(i=1 \ldots 4) . L$ is the waterline length of the catamaran, $B$ is the catamaran demi-hull beam, $T$ is the draught, $C_{B}$ is the block coefficient and $s$ is the distance between the demi-hull centre planes.

The computer code PHP Hard Chine Catamaran Resistance was developed at the Research Centre of the Naval Architecture Faculty from "Dunarea de Jos" University of Galati, in order to determine the total resistance of the catamarans with hard chine forms [8], [14] by using the described procedure.

In the case of the round bilge catamarans forms, the method proposed by Sahoo et al. [23], [24] was selected. The wave resistance coefficient of the catamaran $C_{w c a t}$ was estimated using the following regression formula

$$
\begin{aligned}
& C_{\text {wcat }}=e^{c 1} \cdot\left(\frac{L}{B}\right)^{c 2} \cdot\left(\frac{B}{T}\right)^{c 3} \cdot\left(C_{B}\right)^{c 4} \cdot F_{1} \\
& F_{1}=\left(\frac{L}{\nabla^{1 / 3}}\right)^{c 5} \cdot\left(i_{E}\right)^{c 6} \cdot \beta^{c 7} \cdot\left(\frac{s}{L}\right)^{c 8}
\end{aligned}
$$


where $i_{E}$ is the half angle of entrance and $\beta$ is the deadrise angle at amidships. The volumetric displacement of the demi-hull was noted with $\nabla$. The regression coefficients $c_{i}$ $(\mathrm{i}=1 \ldots 8)$ are given in references [23], [24].

On the basis of this method, the computer code PHP Round Bilge Catamaran Resistance was developed at the Research Centre of the Naval Architecture Faculty from "Dunarea de Jos" University of Galati [9], [15].

Also, a specific module is dedicated to the sailing vessels (including the yachts), in order to estimate the ship resistance in displacement and semi-planning domains.

According to the reference [1], the total yacht resistance may be determined using the following formula

$$
R_{T}=R_{F}+R_{R}+R_{H}+R_{A}
$$

where $R_{R}$ is the residuary resistance and $R_{H}$ is the heel resistance.

The frictional resistance of the yacht $R_{F}$ may be obtained by summing the frictional resistance of the hull, keel and rudder

$$
R_{F}=R_{\text {Fhull }}+R_{\text {Fkeel }}+R_{\text {Frudder }}
$$

These components may be determined by means of the ITTC' 57 ship model correlation line.

The residuary resistance in the displacement domain (in the low speed range, with the Froude number $F_{n}$ between 0.125 $0.45)$ or in the semi-planning domain $\left(F_{n}\right.$ between $0.475-0.75$ ) may be calculated by using the regression relations obtained on the basis of the Delft series, generated by Gerritsma and extended by Stadt and Partners [1]. The Froude number $F_{n}$ is defined by the following relation

$$
F_{n}=\frac{v}{\sqrt{g \cdot L}}
$$

The heel resistance component $R_{H}$ may be determined on the basis of the Froude number, using the expression [1]

$$
R_{H}=0.5 \cdot C_{H} \cdot \rho \cdot v^{2} \cdot S_{\text {Whull }} \cdot F_{n}^{2} \cdot \varphi
$$

where $\varphi$ is the heeling angle of the yacht and $C_{H}$ is the heel coefficient [1].

The aerodynamic resistance of the yacht $R_{A}$ depends on the following three components: the aerodynamic resistance of the hull $R_{A H}$, mast $R_{A M}$ and rig (shrouds and stays) $R_{A R}[1]$

$$
R_{A}=R_{A H}+R_{A M}+R_{A R}
$$

On the basis of this method, the computer code PHP Yacht Resistance was developed at the Research Centre of the Naval Architecture Faculty from "Dunarea de Jos" University of Galati [10], [16].

The mentioned modules of the PHP software platform were used to compute the ship resistance performance of the specific small ships.

Some examples of the ship resistance evaluation for small mono-hulls (including the sailing vessels) and catamarans were presented in the references [14], [15], [16], [18] and [19].

\section{SMALL SHIPS POWERING PER- FORMANCE}

In order to determine the powering performance of the small ships, the following procedure was applied, based on the calculation of the effective power, the delivered power and the brake power.

The effective power may be determined using the relation

$$
P_{E}=R_{T} \cdot v \cdot\left(1+M_{D}\right)
$$

where $M_{D}$ is the power design margin.

The delivered power is calculated on the basis of the following expression

$$
P_{D}=\frac{P_{E}}{\eta_{D} \cdot n_{p}}
$$

where $\eta_{D}$ is the propulsive coefficient and $\mathrm{n}_{\mathrm{p}}$ is the propellers number.

The propulsive efficiency may be determined using the formula

$$
\eta_{D}=\eta_{0} \cdot \eta_{H} \cdot \eta_{R}
$$

where $\eta_{0}$ is the open water propeller efficiency, $\eta_{H}$ is the hull efficiency and $\eta_{R}$ is the relative rotative efficiency. 
The selection of the optimum propeller characteristics is based on the B-Wageningen propeller series.

The brake power of the main engine at full rating (100\% MCR-Maximum Continuos Rating) can be determined using the following expression

$$
P_{B}=\frac{P_{D}}{\eta_{a x} \cdot \eta_{\text {red }} \cdot\left(1-M_{S}\right)}
$$

where $\eta_{a x}$ is the line shaft bearing efficiency, $\eta_{\text {red }}$ is the reduction gear box efficiency and $M_{S}$ is the power service margin.

The brake power of the main engine at service rating can be calculated on the basis of the following relation

$$
P_{B}^{S R}=\frac{P_{B}}{S R}
$$

where $S R$ is the service rating coefficient.

On the basis of the brake power value, the main engine necessary to be installed on board of the small ships is selected from the specific data catalogue.

\section{SMALL SHIPS MANOEUVRING PERFORMANCE}

The small ships manoeuvrability represents an important preliminary hydrodynamic subject and can be determined on the basis of the turning circle test.

The rudder is the usual passive control device, used on the ships in order to convert the water energy into control forces and moments in the horizontal plane. The manoeuvring performance depends on the geometry and the hydrodynamic efficiency of the rudder [17].

The PHP software platform dedicated to the small ships, developed at the Research Centre of the Naval Architecture Faculty from "Dunarea de Jos" University of Galati, includes some specific modules used to determine the hydrodynamics characteristics of the rudder and to estimate the manoeuvring performance in the displacement or planning domain [5].

The estimation of the hydrodynamics characteristics of the rudder was performed by means of the Mordvinov method [3], [4].
The hydrodynamic moment on the rudder stock is determined using the following relation

$$
M=C_{m R H p} \cdot \frac{\rho \cdot v_{c p}^{2}}{2} \cdot A_{R} \cdot b_{R}
$$

where $C_{m R H p}$ is the coefficient of the hydrodynamic moment (with the hull and propeller influences), $v_{c p}$ is the water speed on the deflected rudder, $A_{R}$ is the rudder area and $b_{R}$ is the rudder chord.

The following problems can be solved on the basis of this method: stock;

- the optimum position of the rudder

- the calculation of the total torque (adding the frictional component to the hydrodynamic moment);

- the selection of the steering gear from specific data catalogue;

- the calculation of the rudder stock diameter.

The computer code PHP-NM-MAN-HC was developed at the Research Centre of the Naval Architecture Faculty from "Dunarea de Jos" University of Galati [11], in order to calculate the hydrodynamics characteristics of the rudder by using the Mordvinov method.

In order to estimate the turning circle characteristics of the small ships in the displacement domain, the Mordvinov method can be used, based on the hydrodynamics characteristics of the hull and of the rudder [3], [4], [20].

The following characteristics of the turning motion can be determined: the steady turning diameter, the angular speed, the drift angle, the ship speed and the maximum heeling angle during the steady turning motion.

The computer code PHP-NM-MAN-D was developed at the Research Centre of the Naval Architecture Faculty from "Dunarea de Jos" University of Galati [12], in order to calculate the manoeuvring characteristics of the small ships in the displacement domain, by using the Mordvinov method. 
The manoeuvring performance problem in the case of the planning small ships was also solved by means of the same Mordvinov procedure [3], [4], [21].

The computer code PHP-NM-MAN-G was developed at the Research Centre of the Naval Architecture Faculty from "Dunarea de Jos" University of Galati [13], in order to determine the manoeuvring characteristics of the planning of small ships, using the Mordvinov method.

The above mentioned manoeuvring modules of the PHP software platform were applied to determine the hydrodynamics characteristics of the rudders and the turning circle performance of the small ships, in the displacement and planning domains.

Some practical evaluations of the small ships manoeuvring characteristics, in the displacement and planning domains were presented in the references [20] and [21].

\section{CONCLUDING REMARKS}

The resistance, powering and manoeuvring performances estimation of the small ships is an important preliminary design problem. istinct theoretical methods can be applied in order to solve the mentioned hydrodynamics problems, depending on the number of the hulls and the operating domain (displacement, transient or planning).

In this paper, a software platform dedicated to the evaluation of the resistance, powering and manoeuvring performances of the small ships was described.

A synthetical description of the main theoretical aspects was presented.

The PHP (Preliminary Hydrodynamics Performances) software platform was developed at the Research Centre of the Naval Architecture Faculty from "Dunarea de Jos" University of Galati.

The following small ships hydrodynamics problems may be solved:

- mono-hulls resistance estimation in displacement or transient domains;

- mono-hulls resistance estimation in planning domain;
- sailing vessels resistance estimation in displacement and semi-planning domains;

- catamarans resistance estimation with rounded bilge forms;

- catamarans resistance estimation with hard chine forms;

- powering performance estimation;

- evaluation of the hydrodynamics characteristics of the rudders;

- determination of the optimum position of the rudder stock;

- estimation of the total torque on the rudder stock and selection of the steering gear;

- estimation of the turning circle characteristics of the mono-hulls in the displacement domain; - estimation of the turning circle characteristics of the mono-hulls in the planning domain.

The software platform can be used for didactic applications and applied research activities, dedicated to the hydrodynamics performances estimation, in the preliminary design stage of the small ships.

\section{Acknowledgements}

The paper was supported by the Research Centre of the Naval Architecture Faculty from "Dunarea de Jos" University of Galati, which is greatly acknowledged.

The computer codes in Java language were realised by Alexandru Andoniu, Dorin Iulian Chiracu, George Jagîte and Ana Maria Chiroşcă, during their student research activities.

\section{REFERENCES}

[1]. Larsson, L., Eliasson, R.E., "Principles of yacht design", International Marine, The McGraw-Hill Companies, 2000.

[2]. Molland, A.F., Wellicome, J.F., Couser, P.R., "Resistance experiments on a systematic series of high speed displacement catamaran forms: variation of lengthdisplacement ratio and breadth-draft ratio", Ship Science Report, No. 71, University of Southampton, UK, 1994.

[3]. Mordvinov, B.G., Spravocinic po malotonajnomu sudostroeniu, Sudostroenie Publishing House, St. Petersburg, 1988 (in Russian). 
[4]. Obreja, C.D., "Hydrodynamic particularities of the small ships design", The University Foundation "Dunarea de Jos" Publishing House, Galati, 2004 (in Romanian).

[5]. Obreja, C.D., Pacuraru, S., "Small ships hydrodynamics. Numerical Laboratory", The University Foundation "Dunarea de Jos" Publishing House, Galati, 2016 (in Romanian).

[6]. Obreja, C.D., Andoniu, Al., Chiracu, D.I., "PHP NM-RI-DT computer code", The Research Centre of the Naval Architecture Faculty, "Dunarea de Jos" University of Galati, 2012.

[7]. Obreja, C.D., Andoniu, Al., Chiracu, D.I., "PHP NM-RI-G computer code", The Research Centre of the Naval Architecture Faculty, "Dunarea de Jos" University of Galati, 2012.

[8]. Obreja, C.D., Chiracu, D.I., "PHP Hard Chine Catamaran Resistance computer code", The Research Centre of the Naval Architecture Faculty, "Dunarea de Jos" University of Galati, 2014.

[9]. Obreja, C.D., Chiracu, D.I., "PHP Round Bilge Catamaran Resistance computer code", The Research Centre of the Naval Architecture Faculty, "Dunarea de Jos" University of Galati, 2015.

[10]. Obreja, C.D., Chirosca, A.M., "PHP Yacht Resistance", The Research Centre of the Naval Architecture Faculty, "Dunarea de Jos" University of Galati, 2018.

[11]. Obreja, C.D., Jagite, G., " $P H P N M-M A N-$ $H C$ ", The Research Centre of the Naval Architecture Faculty, "Dunarea de Jos" University of Galati, 2016.

[12]. Obreja, C.D., Jagite, G., " $P H P$ NM-MAN$D$ ”, The Research Centre of the Naval Architecture Faculty, "Dunarea de Jos" University of Galati, 2016.

[13]. Obreja, C.D., Jagite, G., " $P H P N M-M A N$ $G$ ", The Research Centre of the Naval Architecture Faculty, "Dunarea de Jos" University of Galati, 2016.

[14]. Obreja, C.D., Chiracu, D.I., "Practical evaluation of the high-speed catamaran resistance with hard-chine forms", The Annals of "Dunarea de Jos" University of Galati, Fascicle XI-Shipbuilding, pp. 85-88, 2014.

[15]. Obreja, C.D., Chiracu, D.I., "Practical evaluation of high-speed round bilge catamaran resistance", The Annals of "Dunarea de Jos" University of Galati, Fascicle XIShipbuilding, pp. 21-26, 2015.

[16]. Obreja, C.D., Chirila, T.A., "Preliminary computation of yacht resistance components using Delft series", The Annals of "Dunarea de Jos" University of Galati, Fascicle XIShipbuilding, pp. 77-80, 2015.

[17]. Obreja, C.D., "Software platform for manoeuvrability performance estimation in initial ship design", The Annals of "Dunarea de Jos" University of Galati, Fascicle XIShipbuilding, pp. 15-20, 2015.

[18]. Obreja, C.D., "Small ship resistance estimation in displacement and transient domain", Constanta Maritime University Annals, Year XVII, Vol. 25, 2016.

[19]. Obreja, C.D., "Small ship resistance estimation in planning domain", The Annals of "Dunarea de Jos" University of Galati, Fascicle XI-Shipbuilding, pp. 49-52, 2017.

[20]. Obreja, C.D., "Small ship manoeuvring estimation in displacement domain", The Annals of "Dunarea de Jos" University of Galati, Fascicle XI-Shipbuilding, pp. 31-36, 2017.

[21]. Obreja, C.D., "Small ship manoeuvring estimation in planning domain”, The Annals of "Dunarea de Jos" University of Galati, Fascicle XI-Shipbuilding, pp. 5-8, 2018.

[22]. Pham, X.P., Kantimahanthi, K., Sahoo, P., "Wave resistance prediction of hard-chine catamarans through regression analysis", Proceedings of $2^{\text {nd }}$ International Euro Conference on High Performance Marine Vehicles, Hamburg, Germany, pp. 382-394, 2001.

[23]. Sahoo, P.K., Brown, N.A., Salas, M., " $E x$ perimental and CFD study of wave resistance of high-speed round bilge catamaran hull forms", Proceedings of $4^{\text {th }}$ International Euro Conference on High Performance Marine Vehicles, Rome, Italy, 2004.

[24]. Sahoo, P.K., Salas, M., Schwetz, A., "Practical evaluation of resistance of highspeed catamaran hull forms-part I", Ships and offshore structures, Vol.2, Issue 4, pp. 307-324, 2007.

[25]. Schwetz, A., Sahoo, P.K., "Wave resistance of semi-displacement high speed catamarans through CFD and regression analysis", Proceedings of $3^{\text {th }}$ International Euro Conference on High Performance Marine Vehicles, Bergen, Norway, pp. 355-368, 2002.

[26]. Zips, J.M., "Numerical resistance prediction based on results of the VWS hard chine catamaran hull series", Proceedings of $4^{\text {th }}$ International Conference on Fast Sea Transportation, Luebeck, Germany, Vol.1, pp. 67-74, 1995.

Paper received on May $30^{\text {th }}, 2019$ 
